\title{
The Management of Cultural Heritage: the Importance of No Profit Subjects
}

\author{
Carmela Tramontana ${ }^{1, a}$ \\ ${ }^{1}$ Mediterranea University of Reggio Calabria - PAU - Department of Heritage, Architecture, Urban \\ Planning, Via Salita Melissari - 89124, Reggio di Calabria, Italy \\ acarmen.tramontana@unirc.it
}

Keywords: Cultural Heritage, Management Models, Economic - Financial Sustainability, No Profit.

\begin{abstract}
This study aims to contribute to the enhancement of cultural and environmental heritage of Calabria, with the objective to identify the optimal management model, able to achieve results effective, efficient and long lasting, as the effects of mismanagement often determine causes of decay and abandonment of heritage: have been used the verification of the comparative financial sustainability, as suggested by the Legislative Decree 42/2004, between two categories of program manager, profit and no profit, starting from the assumption that the real manager public, owner of a large part of cultural heritage, it is not in the best condition to manage because of multiple factors. From the simulation performed on the Gerace's Cultural Park of History and Memory, it is clear that the subject no profit is the one best suited, so, with the same objectives, and services to be provided within the tariff, it checks the condition of equilibrium between costs and revenues: specifically, determining factor for the attainment of equilibrium is the cost of a no profit entity, that is considerably lower, making use of voluntary unlike a subject who must supply profit instead of real salaries.
\end{abstract}

\section{Introduction}

The geographical position, the peculiarities of the territory, the inherent richness of the region, have made Calabria the nerve center of decisive historical events for the destiny of the Mediterranean, whose effects are still visible in its natural structure, urban and social, thus providing this region of a large number of cultural and environmental values that represent in a certain sense the armor.

The theme of the valorization of this heritage is a much debated topic today on the assumption well-established, the territory represents a reservoir of resources through appropriate actions, including the protection, preservation, and thus the enhancement, may be growth driver, understood as the increase of produced goods and services by the economic system, and for development of the territory, namely the increase and improvement of quality of life, including elements of social, cultural and political life, and, especially for economically disadvantaged areas such as Calabria, still more if those assets declined in its dimension of the system and not a single item on time, as often, however, it happens in most of the reality.

\section{The reference context}

The subfund homogeneous object of the present research, identified by the Unitary Framework of Integrated Planning of the Calabria's Region as Area 11, is made up of six municipalities that fall in the range Calabria's Ionian: Agnana Calabria, Antonimina, Canolo, Ciminà, Gerace, Mammola. In these territories, are recognizable values of character historic - natural - cultural, as characterized by strong attractors that give an integrated cultural and environmental heritage of particular value, as the Aspromonte National Park, the historical-artistic and cultural resources as the testimonies Magna Grecian, Roman, Byzantine, to the Norman period and the Saracen invasions which have contributed to an even recognizable overlap of cultures and identities that have generated the historical centers of value, expression of the cultural landscape of the Aspromonte; among these stands out among all, the medieval village of Gerace. Many, too, the enogastronomic values that link across these territories, together with the presence of hot springs. It is for these many meanings found that this area was the subject of an Integrated Local Development Project (PISL) called 
SLOW LIFE. Traveling between Culture and Nature in the National Park of Aspromonte, from Tre Pizzi to Limina, aimed at the realization of Local Tourist Systems / Local Tourist Destinations, out on the Priority Axes of the Calabria' POR FESR 2007 - 2013, whose objective is to put these values into network and provide services designed to qualify the tourist offer, in terms of accommodation in order to create an integrated tourism offer through measures complementary to each other, in synergy and partnership between public and private, that can enhance, organize, and further qualify the tourist offer of territorial limits, in order to strengthen the attractivity for the full enjoyment of cultural resources, nature, spas and gastronomic existing, having as its overall objective to improve strengthen the competitiveness and attractiveness of the Area territorial [1].

In order to build a network of this, it was obligatory to refer to the integrated planning mode, which pursues the objective of establishing local development on the real needs of the territory and give the different territorial entities play an active role in the identification, selection of the needs and the transformation of these into skilled intervention projects, for which it is necessary to draw up appropriate feasibility studies, considering, therefore, not only the short term, but long-term planning, taking into account in the drafting of these studies, a factor of fundamental importance, which is often underestimated, in the moment in which the investments are addressed: the management.

\section{The problem of management}

The theme of cultural heritage management is an issue of considerable public interest, which often exacerbates the minds of those who are located in the realm of publicists, who do not consider the proposal to those who claim to outsource management services according to the Anglo-Saxon model, such as the National Trust, the best way to manage cultural heritage. That heritage management, however, is a topic of great importance, taken as the time implementing and 'continuous' protection of the moment: in the absence of an appropriate form of management, will not be able to pursue the objectives of conservation and of the protection, because the assets would be subject to constant degradation arising from the use or not of a non-proper use of it, making vain even the most prestigious and effective conservation and restoration actions, will not be able to pursue the objectives of valorisation, since not be possible to promote activities aimed to create awareness of the cultural heritage and to ensure the best conditions for public use and enjoyment of the assets, also in terms of accessibility, not contributing, therefore, the development of culture.

The Legislative Decree 156/2006, in order to find a solution to the mode of economically efficient management of cultural heritage and to raise financial resources aimed at improving the usability of assets, update how pointed out in Articles 112 and 115 of the Code of Cultural Heritage and Landscape concerning of development, simplifies the list of possible forms of management for assets membership to the public, using essentially two ways: direct and indirect specifying that the choice between the two forms of management indicated is implemented through a comparative assessment in terms of financial sustainability and efficiency, based on the objectives defined in advance, in order to justify the choice between direct management and outsourcing: then this choice will rely not on a contingent preference but on a valuation conducted according to criteria that take into account the economic and financial sustainability, effectiveness and targets defined in advance [2] [3] [4]. For direct management shall mean when the management is performed by means of internal organizational structures of the Administration, with appropriate scientific autonomy, organizational, financial and accounting, and equipped technical staff. The government can implement the same direct management as well as a consortium public [5]. For indirect management, we mean when the management is implemented through a third party concession for valorisation, including joint and integrated by government or legal entities established under the same code as the goods belong [5].

Knowing the different modes of management under the Code of Cultural Heritage and Landscape for the cultural heritage of a public nature, has allowed to build a profile of the different types of program manager, public, private for-profit and no-profit organizations, identifying the salient features. 
By analyzing, in summary, the public operator subject, which pursues the logic related to the community, is characterized by a strong managerial rigidity that does not allow, in the field of cultural heritage, opt and implement flexible and changeable, as it would be appropriate. The contingency of increasing budget constraints, the lack of managerial logic, together with the not always adequate staff capacity, denote the many difficulties that such a subject has to face for the management of cultural heritage, with the consequential occurrence of situations that instead of enhancing property, determining instead the degradation and the abandonment, with the aggravating circumstance of not only the loss of the asset in itself and the denial of receipt of the benefit to the community, but also generated substantial cost, thus failing to achieve balance necessary to achieve financial sustainability, or to have such revenues to cover the operating costs.

The private for-profit entity manager has as its ultimate goal to satisfy human needs, directly or indirectly. From the exchange of such goods and / or services resulting revenue, or those elements to remunerate the factors of production. The aim pursued is to achieve a profit to be allocated to the shareholders of the company or the individual entrepreneur, denoting, therefore, lack of attention to public interests. In fact, his work is aimed at achieving a just equilibrium in the medium and long term, seeking to maximize the value of operating income (the difference between costs and revenues): this condition turns out to be necessary for the survival of its activities. It is intended to balance the economic capacity to develop, during his activities revenues in excess of costs so as to remunerate the capital invested in adequate measure, according to the criteria of economy, efficiency and effectiveness.

A specific nature which sets it apart is the fact that must support very high fixed costs, especially the voice of the personnel employed, the main cost item.

The no profit private subject may be united to the for-profit definitely for the fact that it is productive organizations that have as their main purpose the fulfillment of human needs. To achieve this purpose, as for the for-profit subject, must operate his choices so that they can occur under such conditions as to remain the economic balance desirable over time. The propensity to efficiency and effectiveness, however, does not determine the realization of profit, but to create value and sets the conditions necessary to ensure the survival of the organization over time [6]. According to the Framework Law on voluntary activities 266/91, the subject no profit, not for profit, can not distribute in any form to its shareholders, members or employees, profits arising from its activities. This does not mean that the no profit company can not achieve operating surpluses (surplus of revenue over expenditure), but that they must be reinvested in the business. It is also possible to find a high flexibility, due to the use of voluntary labor for the performance of fixed assets: this determines the reduction of fixed costs because the voice of personnel costs would drop significantly compared to for-profit subject, would also employed qualified personnel, since subject was born with a clearly defined purpose, is recognized and therefore entitled in the context in which it operates [7].

\section{The case of study: the Gerace's Cultural Park of the history and memory}

The transaction, which is part of the operations proposed by PISL Slow Life, aimed at usability of the Cultural Attractions, involves the construction of the Gerace's Cultural Park of History and Memory' which occurs through a complex set of actions that affect the materials completion of the recovery and reuse of three religious buildings of historic and artistic value, public property, aimed at localization of cultural functions able to make perceptible the peculiarities of the heritage of the city of Gerace, characterized by multiple layers of settlement and traces of medieval culture . It is characterized by 4 sub-steps:

1. A thousand years of the Diocese in Gerace: the religious tradition. Completion of recovery of the church of St. Martin;

2. The city superimposed. Completion of recovery of the church of S. Maria del Mastro;

3. Centre for Studies and Documentation medieval. Completion of recovery of the church of St. Catherine;

4. Intangible actions for the design and implementation of the Cultural Park. 
Once structured the project in its concrete aspects related to the physical recovery of the monumental buildings and identified for each a reuse compatible with their nature, it is necessary to go to the stage where it is assumed the manager who is best suited to develop the activities of development that the town of Gerace is not in a position to implement due to the absence of performance requirements, capabilities specifically cultural flexibility, causing the same to outsource the management, starting with the selection procedure of the manager, whose first step is expressed by issuing a public tender, perhaps structured on the basis of previous data reconnaissance and accessions of any subjects, gathered through appropriate expressions of interest. It is therefore to outsource indirect three properties for a period of 10 years, through the provision of property to a third party. The program manager, with this in mind, will surely be a private subject, but it will be more appropriate to a subject profit or no-profit? It is in this moment that comes into play the comparative verification of financial sustainability. In this regard, are fixed parameters that will remain the same for the simulation relative to the subject-profit subject for the no profit. First, starting from the services to be performed in the same manner and with the same characteristics, by qualified personnel competent concerning: guided tours of the borough, guided trails for children, college internships; sale to the Book Shop, welcome service at the Cultural Park; library service, organizing conferences and exhibitions.

\section{The verification of the economic and financial sustainability}

The program manager, in any shape it takes the form, in order to provide the services set, will face the costs, which are estimated in virtue of such activities. The following simulation, for this reason, will take account of costs both for the hypothetical no profit subject, is subject to the hypothetical profit organization that will manage the Park. A single cost will be considered in a different way for the two categories: the staff, who for-profit subject will characterize in the provision of real annual wages, while for the no profit subject personnel costs will be calculated having regard to disbursement services as a volunteer, for which they will be as per legislation, only distributed simple reimbursement of expenses. The proceedings used to estimate the costs (and even fall from the third year considered constant throughout the time span of 10 years on the simulation), useful to check the balance of financial management, has made use of the following sources direct and indirect:

- Previous experience of elaboration of management plans already approved by the Region of Calabria;

- Field survey of services similar to those provided by Operation;

- Comparison with local stakeholders in the sector, during of Urban Laboratories;

- In the case of personnel costs, the benchmark was the CNNL FEDERCULTURE and the Provincial Observatory on Tourism.

In particular, for-profit entity, for the cost of personnel should not be considered the amount of the salary, but the cost of labor. The identified sources of revenue derived from the provision of these services for cultural, such as guided tours, organization of University stages, special courses for school, sale of promotional material and entrance to the Park. For the first year was considered an initial influx of about 9000 visitors, as can be deduced from the data provided by the Regional Plan for Sustainable Tourism Development 2011-2013 by the Statistical Service of the Ministry of Culture and by comparison with the local operators in the sector, up to to an estimated 13,700 visitors in its third year, the year when fully implemented, also calculated as a function of the number of beds and services associated with the implementation of projects of PISL and the growing interest shown by studies on cultural tourism (incidence of $93.3 \%$ interest attributed to cultural tourism, the Regional Plan Sustainable Tourism Development 2011-2013).

In order to determine the occurrence of the balance between costs and expected revenues, we proceeded, albeit in summary form but quite comprehensive, to the application of Cost-Revenue [8], financial evaluation methodology intended for private individuals, as it is based on the evaluation criteria of profit; another viable technique applicable, less immediate, however, appears to be the Break Even Point Analysis, a method which allows to find the point of balance between costs and revenues, even graphically. 
As is apparent from Table 1 and Table 2, are distinguished, of course, the situation that would be created for the two types of subject manager.

Among the operating costs (fixed and variable) for both profiles include purchases and consumption of goods and services, routine maintenance, maintenance utilities, royalties and unforeseen events. ultimately the cost of personnel to carry out the planned activities: will be involved the following professionals: a Book Shop operator, operators for the cleaning of the interior spaces, a receptionist, a clerk at the library service and a director, who for simulation on the non-profit will be identified in the figure of the president of the hypothetical association, and because of this, his work coordination, will be exclusively on a voluntary basis, otherwise profit from the subject. For the hypothesis on the subject nonprofit staff will be 'recruited' among the members of the association, where possible, legitimizing their volunteer activities with the aim of cutting cultural association.

Reference was made, as mentioned earlier FEDERCULTURE the National Collective Bargaining Agreement of 2011 [9], following the directives for both the framing of professionals and to identify the correct salary according to the category identified and the cost of labor relative to profit entity, which as mentioned, unlike the non-profit entity, proffering real wages to be paid for 14 months. Among the falls tariff arising out of activities include the figures relating to guided tours, rental of audio guides, organization of internships and educational activities, entrance to the Park and the sale of information material to the Book Shop.

\section{Conclusions}

From the comparison between the two situations presented, it is clear that for-profit entity, having to bear costs more than the subject no profit attributable to the high cost of personnel, Fig.2, not occurs the economic and financial equilibrium, resulting unsustainable in a scenario which shows a negative balance, being the higher costs of revenues. For the no profit entity, on the contrary, the balance is verified, and in general is more likely to occur, identifying himself as the best solution for the management of the assets in question, as required by the Code of Cultural Heritage and Landscape.

This solution would lead to the persistence of long-lasting enhancement activities to the cultural heritage of the Park, but in general, all of the cultural heritage, which otherwise, as often happens, would remain valid attempts not intended to achieve the desired results, even with best restorations.

If the overall goal is to protect, preserve and promote the cultural and environmental heritage, ensuring its permanence to future generations, and at the same time, 'use' this heritage as a tool for growth and sustainable development for particularly disadvantaged areas such as that relating to case study of this analysis, it is necessary, therefore, to make use of the many valid and no profit private entities that affect the region.

Table 1, Balance between costs and revenues no profit subject

\begin{tabular}{|l|r|r|r|r|}
\hline \multirow{2}{*}{ operating costs } & \multicolumn{4}{|c|}{ no profit subject } \\
\cline { 2 - 5 } & $\mathbf{1}$ & $\mathbf{2}$ & $\mathbf{3}$ & $\mathbf{4}$-10 \\
\hline $\begin{array}{l}\text { A. Purchases and consumption of goods and } \\
\text { services }\end{array}$ & $€ 9.245,00$ & $€ 17.460,00$ & $€ 29.510,00$ & $€ 29.510,00$ \\
\hline B. Ordinary maintenance & $€ 980,00$ & $€ 1.410,00$ & $€ 1.790,00$ & $€ 1.790,00$ \\
\hline C. Extraordinary maintenance & $€ 0,00$ & $€ 4.500,00$ & $€ 9.000,00$ & $€ 9.000,00$ \\
\hline D. Other costs: Utilities & $€ 5.225,00$ & $€ 6.050,00$ & $€ 6.400,00$ & $€ 6.400,00$ \\
\hline E. Other costs: Fixed & $€ 3.700,00$ & $€ 3.700,00$ & $€ 3.700,00$ & $€ 3.700,00$ \\
\hline F. Other costs: Variables & $€ 4.050,00$ & $€ 5.950,00$ & $€ 6.750,00$ & $€ 6.750,00$ \\
\hline G. Staff & $€ 35.900,00$ & $€ 42.880,00$ & $€ 55.300,00$ & $€ 55.300,00$ \\
\hline TOTALE $\left(\sum\right.$ A - G) & $€ \mathbf{5 9 . 1 0 0 , 0 0}$ & $€ 81.950,00$ & $€ \mathbf{1 1 2 . 4 5 0 , 0 0}$ & $€ 112.450,00$ \\
\hline & & & & \\
\hline Financial returns & \multicolumn{5}{|c|}{ Years of management } & \\
\hline & $\mathbf{1}$ & $\mathbf{2}$ & $\mathbf{3}$ & $\mathbf{4 ~ - 1 0}$ \\
\hline A. tariff returns & $€ 59.100,00$ & $€ 81.950,00$ & $€ 112.450,00$ & $€ 112.450,00$ \\
\hline
\end{tabular}




\begin{tabular}{|c|c|c|c|c|}
\hline TOTAL & € 59.100,00 & $€ 81.950,00$ & $€ 112.450,00$ & $€ \quad 112.450,00$ \\
\hline Management Financial Balance & \multicolumn{4}{|c|}{ Years of management } \\
\hline & 1 & 2 & 3 & $4-10$ \\
\hline A. Total Operating Costs & $€ 59.100,00$ & $€ 81.950,00$ & $€ 112.450,00$ & $€ 112.450,00$ \\
\hline B. Total returns tariff & $€ 59.100,00$ & $€ 81.950,00$ & $€ 112.450,00$ & $€ 112.450,00$ \\
\hline REMAINING (B - A) & € 0,00 & € 0,00 & $€ 0,00$ & $€ \quad 0,00$ \\
\hline CUMULATIVE REMAINING peryear & $€ 0,00$ & $€ 0,00$ & $€ 0,00$ & $€ \mathbf{0 , 0 0}$ \\
\hline
\end{tabular}

Table 2, Balance between costs and revenues profit subject

\begin{tabular}{|c|c|c|c|c|}
\hline \multicolumn{5}{|c|}{ profit subject } \\
\hline \multirow[t]{2}{*}{ operating costs } & \multicolumn{4}{|c|}{ Years of management } \\
\hline & 1 & 2 & 3 & $4-10$ \\
\hline $\begin{array}{l}\text { A. Purchases and consumption of } \\
\text { goods and services }\end{array}$ & $€ 9.245,00$ & $€ 17.460,00$ & $€ 29.510,00$ & $€ 29.510,00$ \\
\hline B. Ordinary maintenance & $€ 980,00$ & $€ 1.410,00$ & $€ 1.790,00$ & $€ 1.790,00$ \\
\hline C. Extraordinary maintenance & $€ 0,00$ & $€ 4.500,00$ & $€ 9.000,00$ & $€ 9.000,00$ \\
\hline D. Other costs: Utilities & $€ 5.225,00$ & $€ 6.050,00$ & $€ 6.400,00$ & $€ 6.400,00$ \\
\hline E. Other costs: Fixed & $€ 3.700,00$ & $€ 3.700,00$ & $€ 3.700,00$ & $€ 3.700,00$ \\
\hline F. Other costs: Variables & $€ 4.050,00$ & $€ 5.950,00$ & $€ 6.750,00$ & $€ 6.750,00$ \\
\hline G. Staff & $€ 67.286,45$ & $€ 96.123,50$ & $€ 134.572,90$ & $€ 134.572,90$ \\
\hline TOTAL $\left(\sum \mathrm{A}-\mathrm{G}\right)$ & $€ \mathbf{9 0 . 4 8 6 , 4 5}$ & $€ 135.193,50$ & $€ 191.722,90$ & $€ 191.722,90$ \\
\hline \multirow[t]{2}{*}{ Financial returns } & \multicolumn{4}{|c|}{ Years of management } \\
\hline & 1 & 2 & 3 & $4-10$ \\
\hline A. Tariff returns & $€ 59.100,00$ & $€ 81.950,00$ & $€ 112.450,00$ & $€ 112.450,00$ \\
\hline TOTAL & $€ 59.100,00$ & $€ 81.950,00$ & $€ 112.450,00$ & $€ 112.450,00$ \\
\hline \multirow[t]{2}{*}{ Management Financial Balance } & \multicolumn{4}{|c|}{ Years of management } \\
\hline & 1 & 2 & $\mathbf{3}$ & $4-10$ \\
\hline A. Total Operating Costs & $€ 90.486,45$ & $€ 135.193,50$ & $€ 191.722,90$ & $€ 191.722,90$ \\
\hline B. Total returns tariff & $€ 59.100,00$ & $€ 81.950,00$ & $€ 112.450,00$ & $€ 112.450,00$ \\
\hline REMAINING (B - A) & $-€ 31.386,45$ & $-€ 53.243,50$ & $-€ 79.272,90$ & $-€ 79.272,90$ \\
\hline CUMULATIVE REMAINING per year & $-\mathbf{3 1 . 3 8 6 , 4 5}$ & $-€ 84.629,95$ & $-€ 163.902,85$ & $-€ 243.175,75$ \\
\hline
\end{tabular}

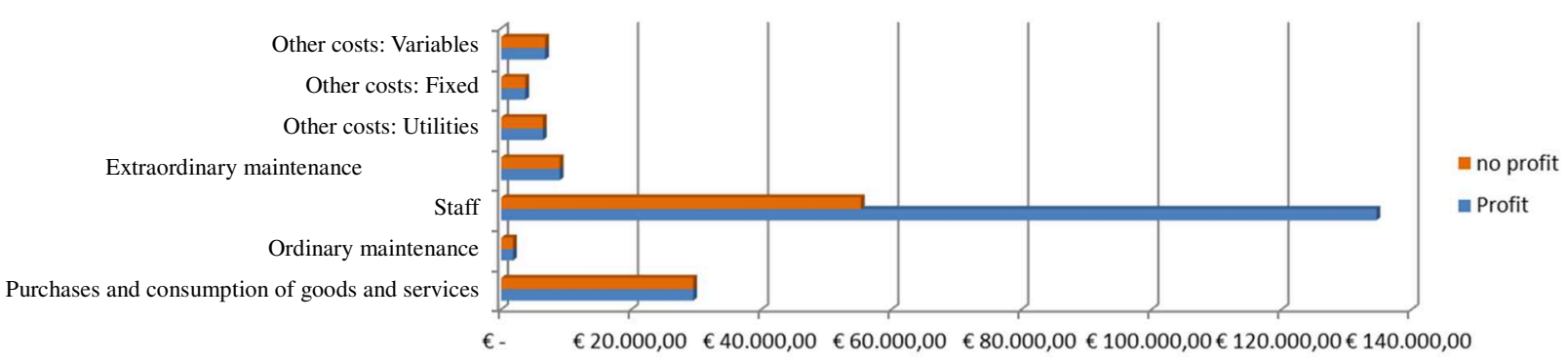

Fig. 2 Comparison simulation cost-benefit subject-profit and no profit

\section{Rererences}

[1] Formulario PISL SLOW LIFE.

[2] P. Bilancia: La valorizzazione dei Beni culturali tra pubblico e privato, Franco Angeli, Milano (2006)

[3] C. M. Golinelli: La valorizzazione del patrimonio culturale: verso la definizione di un modello di governance: cultura, impresa e territorio, Giuffrè, Milano (2008) 
[4] P. Seddio: La gestione integrata di reti e sistemi culturali: contenuti, esperienze e prospettive, Franco Angeli, Milano (2013)

[5] Codice dei beni culturali e del paesaggio, Decreto legislativo n.42 del 22 gennaio 2004 e successive modifiche

[6] L. Hinna: Appunti di economia aziendale, CEDAM (2008)

[7] F. Calabrò, L. Della Spina: The cultural and environmental resources for sustainable development of rural areas in economically disadvantaged contexts. Economic-appraisals issues of a model of management for the valorisation of public assets. In 3rd International Conference on Energy, Environment and Sustainable Development (ICEESD 2013). Advanced Materials Research Vols. 869-870 (2014) pp 43-48 (C) (2014) Trans Tech Publications, Switzerland doi:10.4028/www.scientific.net/AMR.869-870.43, (2014)

[8] F. Prizzon: Gli investimenti immobiliari: analisi di mercato e valutazione economicofinanziaria degli interventi, Celid, Torino (2001)

[9] Information on http://www.federculture.it/wp-content/uploads/2013/01/CCNL_FED_2008_ 2011_edizione-per-stampa.pdf 